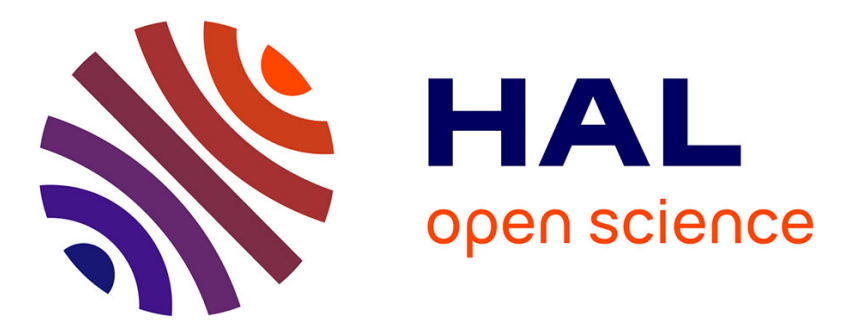

\title{
The beta-catenin pathway is activated in focal nodular hyperplasia but not in cirrhotic FNH-like nodules.
}

Sandra Rebouissou, Gabrielle Couchy, Louis Libbrecht, Charles Balabaud, Sandrine Imbeaud, Charles Auffray, Tania Roskams, Paulette Bioulac-Sage, Jessica Zucman-Rossi

\section{To cite this version:}

Sandra Rebouissou, Gabrielle Couchy, Louis Libbrecht, Charles Balabaud, Sandrine Imbeaud, et al.. The beta-catenin pathway is activated in focal nodular hyperplasia but not in cirrhotic FNHlike nodules.. Journal of Hepatology, 2008, 49 (1), pp.61-71. 10.1016/j.jhep.2008.03.013 . inserm00329509

\section{HAL Id: inserm-00329509 https://www.hal.inserm.fr/inserm-00329509}

Submitted on 11 Oct 2008

HAL is a multi-disciplinary open access archive for the deposit and dissemination of scientific research documents, whether they are published or not. The documents may come from teaching and research institutions in France or abroad, or from public or private research centers.
L'archive ouverte pluridisciplinaire HAL, est destinée au dépôt et à la diffusion de documents scientifiques de niveau recherche, publiés ou non, émanant des établissements d'enseignement et de recherche français ou étrangers, des laboratoires publics ou privés. 


\section{The beta-catenin pathway is activated in focal nodular hyperplasia but not in cirrhotic FNH-like nodules}

Rebouissou Sandra ${ }^{12}$, Couchy Gabrielle ${ }^{12}$, Libbrecht Louis $^{3}$, Balabaud Charles ${ }^{4}$, Imbeaud Sandrine ${ }^{67}$, Auffray Charles ${ }^{6}$, Roskams Tania $^{3}$, Bioulac-Sage Paulette ${ }^{48}$, Zucman-Rossi Jessica ${ }^{12}$ *

${ }^{1}$ Genomique Fonctionnelle des Tumeurs Solides INSERM : U674, Université Denis Diderot - Paris VII, Hopital Saint-Louis - IFR 105 PARIS VII 27, Rue Juliette Dodu 75010 PARIS ,FR

2 IUH, Institut Universitaire d'Hématologie Université Denis Diderot - Paris VII, Paris,FR

${ }^{3}$ Liver Research Unit of the Laboratory of Morphology and Molecular Pathology University of Leuven, BE

${ }^{4}$ Fibrose hépatique et cancer du foie INSERM : U889, Université Victor Segalen - Bordeaux II, IFR66, 146 rue léo saignat, 33076 Bordeaux Cedex, FR

5 Service de Hépato-gastroentérologie CHU Bordeaux, Hôpital Saint-André, Bordeaux,FR

${ }^{6}$ Genexpress, Génomique Fonctionnelle et Biologie Systémique pour la Santé CNRS : UMR7091, Université Pierre et Marie Curie - Paris VI , 7 rue Guy Moquet, BP8, 94801 Villejuif cedex,FR

${ }^{7}$ CGM, Centre de génétique moléculaire CNRS : UPR2167, bat. 26 Av de la terrasse 91198 GIF SUR YVETTE CEDEX,FR

8 service d'anatomie pathologique CHU Bordeaux, Groupe hospitalier Pellegrin, Bordeaux, FR

* Correspondence should be adressed to: Jessica Zucman-Rossi <zucman@cephb.fr>

\section{Abstract \\ Background \& Aims}

Focal nodular hyperplasias (FNHs) are benign liver lesions considered to be a hyperplastic response to increased blood flow in normal liver. In contrast, FNH-like occur in cirrhotic liver but share similar histopathological features. To identify biological pathways deregulated in FNH, we conducted a transcriptome analysis.

\section{Methods}

Gene expression profiles obtained in FNH and normal livers were compared. Differentially-expressed genes were validated using quantitative-RT-PCR in 70 benign liver tumors including FNH-like lesions.

Results

Among the deregulated genes in FNHs, 19 displayed physiological restricted distribution in the normal liver. All six perivenous genes were up-regulated in FNH, whereas 13 periportal genes were down-regulated. Almost all these genes are known to be regulated by $\beta$ -catenin. Glutamine synthetase was markedly overexpressed in anastomosed areas usually centered on visible veins. Moreover, activated hypophosphorylated $\beta$-catenin protein accumulated in FNH in the absence of activating mutations. These results suggest the zonated activation of the $\beta$-catenin pathway in FNH, whereas the other benign hepatocellular tumors, including FNH-like lesions, demonstrated an entirely different pattern of $\beta$-catenin expression.

Conclusions

In FNH, increased activation of the $\beta$-catenin pathway was found restricted to enlarged perivenous areas. FNH-like nodules may have a different pathogenetic origin.

MESH Keywords Adult ; Aged ; Carcinoma, Hepatocellular ; metabolism ; pathology ; physiopathology ; Down-Regulation ; genetics ; Extracellular Matrix ; genetics ; metabolism ; Female ; Focal Nodular Hyperplasia ; metabolism ; pathology ; physiopathology ; Gene Expression Profiling ; Humans ; Liver Cirrhosis ; metabolism ; pathology ; physiopathology ; Liver Neoplasms ; metabolism ; pathology ; physiopathology ; Male ; Middle Aged ; RNA, Messenger ; metabolism ; Reverse Transcriptase Polymerase Chain Reaction ; Up-Regulation ; genetics ; beta Catenin ; genetics ; metabolism

Author Keywords Focal nodular hyperplasia ; zonation ; ß-catenin ; glutamine synthetase ; benign tumor ; diagnostic markers ; transcriptome ; microarray.

\section{Introduction}

Focal nodular hyperplasia (FNH), first described by Edmondson (1), is the second most common benign liver tumor, outnumbered only by hemangioma. FNH usually occurs in women 20-50 years old. A relation between FNH and oral contraceptive use has been reported but is disputed (2). Classical FNH is characterized by a central stellate fibrous region containing malformed vascular structures (3 ). The solitary central artery with high flow and the absent portal vein give the lesions a characteristic radiological appearance (4) in more than $80 \%$ of FNH cases. However, some classical FNHs, mainly those smaller than $3 \mathrm{~cm}$, have no central scar at pathological examination 
(5). In all cases, the treatment of FNH is conservative because there is very low risk of complications such as bleeding, and malignant transformation has not yet been proven (6).

FNH typically occurs in normal or almost normal liver. The lesion is multinodular, composed of nearly normal hepatocytes arranged in 1-2-cell-thick plates. Bile ductules are usually found at the interface between hepatocytes and fibrous regions $(7,8)$. It is thought that increased arterial flow hyperperfuses the local parenchyma, leading to secondary hepatocellular hyperplasia. FNH is therefore considered a hyperplastic response to increased blood flow, rather than a neoplastic process $(3,9,10)$. Various vascular abnormalities such as telangiectases, hereditary hemorrhagic telangiectasia, arteriovenous malformation, and anomalous venous drainage may be present, especially in patients with multiple FNHs.

Clonal analysis demonstrated the reactive polyclonal nature of liver cells in FNH in $60-100 \%$ of cases, depending on the series (11-15 ). Other studies analyzing chromosome gains and losses by comparative genomic hybridization, allelotyping, or karyotyping identified chromosome alterations indicating a clonal origin of the FNH nodules in 14-50\% of cases $(2,15,16)$. However, genetic analysis of FNH did not demonstrate somatic gene mutations in CTNNB1, TP53, TCF1 or APC $(15,17,18)$. Recently, it was shown that two angiopoietin genes (ANGPT1 and ANGPT2) involved in vessel maturation have altered mRNA expression levels, with a consistently increased ANGPT1/ANGPT2 ratio in FNH.(14, 15)

Focal nodular hyperplasia-like (FNH-like) nodules are lesions arising in cirrhotic liver that closely resemble FNH at both the morphological and radiological levels $(19,20)$. It has been hypothesized that FNH-like nodules arise as a local hyperplastic response to vascular alterations $(20,21)$ known to occur in liver cirrhosis $(3)$. However, the exact pathogenesis of FNH-like nodules remains to be elucidated.

To better understand the pathophysiology of FNH, we searched for genes deregulated in FNH by conducting a combined cDNA and oligonucleotide transcriptomic analysis exploring expression of more than 15,000 different genes. In this experiment, transcriptome profiles of eight FNHs were compared to six non-tumor liver samples. After the analysis, selected genes belonging to the most strongly activated or inactivated pathways were validated using quantitative RT-PCR in a larger series of 70 benign liver tumors including FNH, hepatocellular adenomas (HCA), macroregenerative and dysplastic cirrhotic nodules, and FNH-like lesions.

\section{Material and Methods}

\section{Patients and Samples}

A series of 11 FNHs, 15 HCAs, 6 normal liver tissues [including samples taken at a distance from HCAs (3), FNHs (1), and hemangiomas (2)], 8 cirrhotic nodules [including 3 high-grade dysplastic nodules (HGDN), 1 low-grade dysplastic nodules (LGDN), and 4 macroregenerative nodules (MRN)], 11 FNH-like nodules, and 19 samples of random cirrhotic liver [including samples taken at a distance from hepatocellular carcinoma (8), FNH-like nodules (7), and dysplastic nodules (4)] were collected at the University Hospital of Bordeaux and Leuven. HCAs were classified as described previously; $(22,23)$ five cases were HNF1 $\alpha$-inactivated, five were $\beta$-cateninmutated, and the remaining five HCAs were non-mutated and inflammatory. For all cases included in this study, full clinical and morphological data were available and are summarized in Table 1. Frozen tissue samples were available for all cases, and the prerequisite to include samples in the study was an adequate sampling of fresh and fixed liver tissue. This study was conducted with the authorization of our local ethics committees (CCPPRB Paris Saint-Louis, France, and Committee from the University Hospitals, Leuven).

For each case, tissue from surgical samples including the nodules and corresponding non-tumor tissue was cut into thin slices. A representative portion of the nodule, as well as of the non-tumor liver, was immediately frozen in liquid nitrogen and stored at $-80^{\circ} \mathrm{C}$ until used for molecular studies. Paraffin tissue sections were routinely stained with H\&E and Masson's trichrome for diagnostic purposes. Pathological diagnosis of FNH and HCA was made on the basis of classical criteria $(7,8)$.

DNA and RNA were extracted as described previously.(15) DNA was quantified by fluorometry (Fluoroskan Thermo Labsystem, Cergy-Pontoise, France). The quality of DNA and RNA was assessed by gel electrophoresis followed by staining with ethidium bromide, and degraded samples were excluded. RNA was accepted for quantitative RT-PCR if the 28S/18S ratio was greater than 1 . For microarray analysis, RNA was analyzed by Agilent Bioanalyzer profiling, and RNA was qualified if the $28 \mathrm{~S} / 18 \mathrm{~S}$ ratio was greater than 1.5 and if the RNA was not degraded.

\section{Microarray Analysis}

Transcriptional profiling of FNH lesions and non-tumor liver tissues was performed using two different microarray approaches (Affymetrix oligonucleotide GeneChips U133 and a cDNA microarray). Minimum Information about a Microarray Experiment (MIAME)-compliant data were deposited in Gene Expression Omnibus (GEO) at NCBI (http://www.ncbi.nlm.nih.gov/geo/) and are accessible through GEO series accession number GSE9536. The characteristics of the in-house manufactured cDNA array are described in Graudens et al. 2006 Additional data file 2 (24). The detailed procedure for the gene array analysis is provided in the supplementary 
material and methods. Gene ontology (GO) categories that were significantly over-represented in FNH were determined by the hypergeometric test using the web-based tool GOTree Machine (GOTM) (http://bioinfo.vanderbilt.edu/gotm/). Distribution in GO categories of genes significantly up-regulated and down-regulated in FNH were compared to the distribution of the overall genes included in the HG-U133A Affymetrix array. GO categories were considered significantly enriched when the P-value was less than 0.01 .

\section{Quantitative RT-PCR}

Quantitative RT-PCR was performed as described previously (25) using pre-designed primers and probe sets from Applied Biosystems for the detection of R18S, NTS, HAL, ANGPT1, ANGPT2, GLUL, GPR49 (LGR5), SDS and CTNNB1. Ribosomal 18S RNA (R18S) was used for the normalization of expression data. The relative amount of mRNA in samples was determined using the 2- $\Delta \triangle \mathrm{CT}$ method, where $\Delta \Delta \mathrm{CT}=(\mathrm{CTtarget-CTR} 18 \mathrm{~S})$ sample $-(\mathrm{CTtarget}-\mathrm{CTR} 18 \mathrm{~S})$ calibrator. Final results were expressed as the $\mathrm{n}$-fold differences in target gene expression in tested samples compared with the mean expression value of non-tumor tissues.

\section{Immunohistochemistry}

Immunostaining was performed on 5- $\mu \mathrm{m}$ sections of formalin-fixed, paraffin-embedded liver samples using a Dako autostainer. A monoclonal antibody against $\beta$-catenin (1:200, BD Biosciences 610153) and a biotinylated mouse antibody against glutamine synthetase (1:400, BD Biosciences) were used for immunostaining. Prior to immunostaining, endogenous peroxidase was blocked, and antigen retrieval was performed in a bain-marie with $0.001 \mathrm{M}$ citrate buffer, $\mathrm{pH}$ 6, at $98^{\circ} \mathrm{C}$. Detection was amplified by the Dako Envision system.

\section{Western Blotting}

Total protein extracts were obtained after tissue homogenization in RIPA lysis buffer (Santa Cruz Biotechnology), and protein concentration was determined using a Pierce BCA protein assay kit. A mouse monoclonal antibody specific for the dephosphorylated, active form of $\beta$-catenin (Upstate Biotechnology, 05-665) was used at a 1:500 dilution. Rabbit polyclonal antibodies were used at a 1:500 dilution for the detection of GSK3 $\beta$ and phospho GSK3 $\beta$ ser9 (Cell Signalling). Ponceau Red staining was used to evaluate protein loading and to normalize the signals. Detection was performed using the ECL SuperSignal West Pico Chemiluminescent Substrate (Pierce) and horseradish peroxidase-conjugated anti-mouse IgG (1:4000, Amersham) as the secondary antibody.

\section{Statistical Analysis}

All reported values are mean \pm SD. Statistical analysis was performed using GraphPad Prism version 4 software, and significance was determined using the nonparametric Mann-Whitney test for unpaired data. A difference was considered significant at $\mathrm{P}<0.05$.

\section{Results}

\section{Identification of Overexpressed Genes Encoding Proteins of the Extracellular Matrix}

Analysis of the Affymetrix and cDNA microarray results revealed 240 and 284 genes that were respectively significantly up- and down-regulated in FNH compared to control non-tumor liver samples (Supplementary Table 1). We analyzed these sets of genes to identify biological pathways that were specifically altered. Using a gene ontology-based analysis, we identified several GO categories that were significantly over-represented in FNH (Supplementary Table 2). Among the up-regulated genes in FNH, the extracellular matrix and cell adhesion terms achieved the highest degree of significance $\left(\mathrm{P}=6.10^{-22}\right.$ and $\mathrm{P}=8.10^{-12}$ respectively) (Table 2). The overexpression of the genes encoding proteins of the extracellular matrix is consistent with the presence of fibrosis in most cases of typical FNH, particularly in the fibrous scar area. In FNH, fibrosis appears as a blue area as revealed using trichrome staining (Fig. 1A and B) or is also immunostained using anti-collagen IV antibodies (Fig. 1C-E). This profile of expression is characteristic of the TGF- $\beta$-dependent pathways. Accordingly, we identified a two-fold overexpression of the TGF- $\beta 1$ gene in FNH, as well as overexpression of other key genes involved in fibrogenesis such as PDGFA and PDGFRB. A smooth muscle actin (SMA) staining was observed in myofibroblasts present at the periphery and within the fibrotic area (Fig. 1G-H). These results are consequently consistent with an activation of the TGF $\beta$ pathway in cells located around the central fibrous scar.

\section{Expression of Zonated Genes is altered in FNH}

Nineteen regulated genes were identified whose expression is physiologically zonated in the hepatic lobule. In addition, the expression of these genes is known or was previously suggested to be regulated by $\beta$-catenin (Table 3) (26, 27). Among these, the expression of 13 genes physiologically expressed in the periportal area was down-regulated in FNH. Moreover, the expression of six genes normally expressed in the perivenous area was up-regulated in FNH nodules, suggesting altered zonation in FNH. To further explore this phenomenon, we analyzed the architectural distribution of glutamine synthetase (GS), a well characterized overexpressed protein in FNH that is physiologically expressed in only one or two plates of hepatocytes immediately adjacent to the central veins in normal liver (Fig. 1I ). In FNH, we observed the overexpression of GS in hepatocytes that were heterogeneously distributed in the nodules. A systematic analysis of the staining architecture showed a non-random distribution of the highly stained hepatocytes over relatively large areas, often 
anastomosed in "map-like" patterns centered on central veins, whereas they remained at a distance from fibrous bands (Fig. 1J and 1K). This zonal distribution pattern of GS expression in FNH strongly differs from the homogeneous staining usually observed in $\beta$-cateninmutated adenomas (22).

The expression of GLUL, the gene encoding GS, is known to be up-regulated by $\beta$-catenin (28). Accordingly, we found that GLUL mRNA overexpression significantly correlated with a slight but significant CTNNB1 (the gene encoding $\beta$-catenin) mRNA overexpression in FNH compared with normal liver tissues $\left(r^{2}=0.33, P=0.016\right.$, Fig. 1L). However, immunohistochemical analysis of FNH nodules using a $\beta$-catenin antibody did not show any abnormal $\beta$-catenin localization. $\beta$-catenin was membranous in all hepatocytes, without significant cytoplasmic or nuclear accumulation, even in hepatocytes that overexpressed GS (Fig. 1M-O). Despite no detectable variation of the total $\beta$-catenin expression in hepatocytes of $\mathrm{FNH}$, we observed the overexpression of the active, unphosphorylated $\beta$-catenin protein in FNH compared to normal liver samples (Fig. 1P). Consistent with $\beta$-catenin activation in FNH, our transcriptomic analysis revealed at least seven additional genes known to be regulated by the $\beta$-catenin pathway but whose physiological localization in the lobule was unknown (Table 3). Taken together, these results suggest the up-regulation of the $\beta$-catenin signaling pathway in areas surrounding the veins of FNH nodules. This up-regulation is related to overexpression of the active form of $\beta$-catenin in the absence of CTNNB1 -activating mutations, as evidenced in 11 screened FNH samples. As activated $\beta$-catenin signaling is a known readout of Wnt signaling, we compared the expression levels of Wnt regulators in FNH and normal liver tissues. We did not find any significant differences in GSK3 $\beta$ and phospho-GSK3 $\beta$ ser9 expression using western blotting (Supplementary Fig. 1). Similarly, no significant difference was observed regarding the expression levels of AXIN1, WNT (14 genes analyzed), FZD (Frizzled receptors) (9 genes analyzed), DVL (3 genes analyzed), LRP5 and LRP6 mRNA (Supplementary Fig. 2). Surprisingly, against the hypothesis of a $\beta$-catenin activation through APC silencing, we found a mild but significant overexpression of the APC transcript in FNH (2-fold) when compared to non-tumor livers ( Supplementary Fig. 2).

\section{Expression of the FNH-deregulated Genes in Other Types of Benign Hepatocellular Tumors}

In a series of 70 liver samples including cirrhotic and normal tissues, different subtypes of adenomas, typical FNH nodules, and FNH-like, dysplastic, and macroregenerative nodules developed in cirrhosis, we examined the specificity of FNH-deregulated genes as identified in our microarray analysis or as described previously in the literature (all the data are provided in the supplementary Table 3). The ratio of expression of two angiopoietin genes, ANGPT1/ANGPT2, which was previously shown to be increased in FNH, (29) demonstrated a significantly increased mean -fold change of expression $(9.5 \pm 6.5)$ in FNH compared with non-tumor liver tissues. However, in our series, the ANGPT1/ANGPT2 ratio also increased significantly, although at a lower level, in cirrhosis-related samples including random cirrhosis $(3.9 \pm 0.4)$, regenerative and dysplastic nodules $(7.5 \pm 0.9)$, and FNH-like nodules (4 \pm 0.6$)$ (Fig. 2). In contrast, the overexpression of the NTS transcript, which encodes neurotensin, was observed specifically in FNH (Fig. 2). The ratio of expression of NTS/HAL was fully specific and sensitive to discriminate FNH from the other benign tumors (Fig. 2).

The microarray results indicating significant overexpression in FNH of the $\beta$-catenin target genes GLUL, GPR49, and TBX3 were confirmed using quantitative RT-PCR (Fig. 2 and data not shown). Interestingly, overexpression was lower than that observed in $\beta$-catenin -mutated adenomas. The other subtypes of lesions demonstrated normal or significantly decreased expression levels of the $\beta$-catenin target genes compared to FNH (Fig. 2). Similarly, two periportal genes, SDS and HAL, which encode the serine dehydratase and histidine amomnia lyase, respectively, were down-regulated specifically in FNH and $\beta$-catenin-mutated adenomas (Fig. 2).

Interestingly, FNH-like nodules demonstrated an expression profile similar to those of other cirrhotic samples but different from the profile observed in typical FNH. In particular, in FNH-like nodules, the $\beta$-catenin-induced perivenous genes encoding GS and GPR49 were significantly down-regulated compared with non-tumor liver and FNH nodules (Fig. 2). Consistent with this result, very little parenchymal GS staining was observed in FNH-like nodules (Fig. 3). Some parenchymal staining was observed around venous structures, in addition to the ductular reaction, of FNH-like nodules. Because ductules occupy only a small area of FNH-like nodules and no parenchymal GS staining was detectable, no GS over-expression was observed at the RT-PCR level. However, the immunohistochemical pattern of GS expression was distinct from that of FNH, thus confirming that FNH-like nodules represent a separate entity. Moreover, in FNH-like nodules, neurotensin and the selected genes displaying periportal localization were not found differentially expressed when compared to non-tumor liver tissues by quantitative RT-PCR (Fig. 2). In fact, FNH-like nodules showed similar expression patterns as other cirrhotic lesions. Consequently, our results support the idea that FNH-like nodules have a pathophysiological origin different from that of typical FNH.

\section{Discussion}

In the present work, we carried out a transcriptomic analysis which revealed the molecular pathways altered in FNH. For the first time, activation of the $\beta$-catenin pathway was demonstrated in these tumors. Recently, $\beta$-catenin was identified as a master actor of hepatocyte proliferation, liver regeneration, hepatocyte metabolism, and liver development and as a master regulator of liver zonation (26, 30-34). In normal hepatocytes, $\beta$-catenin and its known target genes, such as GS, are expressed exclusively in the immediate perivenous areas (28, 35 
). This zonated defined pattern of expression differs from that observed in $\beta$-catenin-activated HCA or carcinoma, which usually shows more diffuse cytoplasmic GS staining and nuclear $\beta$-catenin staining, in accordance with the monoclonal origin of the $\beta$-catenin-activating mutations in these tumors $(8,30)$.

In FNH, $\beta$-catenin activation showed a heterogeneous distribution along the hepatocellular nodules, with a characteristic architectural distribution over relatively large areas, sometimes centered on visible veins and usually remaining at a distance from fibrous bands. This specific $\beta$-catenin expression pattern may be interpreted as the result of an altered hepatocyte zonation in FNH leading to increased $\beta$ -catenin gradient starting from the veins. Because FNHs are most frequently polyclonal tumors, it is not surprising to find a heterogeneous distribution of $\beta$-catenin pathway activation in the absence of gene mutation (11, 13-16).

In FNH, sinusoidal blood flow is modified by arteriohepatic hyperperfusion, and sinusoids are directly irrigated by inlet arterioles coming from fibrous septa $(3,10)$. The abnormal arteries drain indirectly into sinusoids via capillaries in the fibrous septa, leading to a modified sinusoidal endothelial cell phenotype (9, 36-38). This situation is entirely different from the normal lobulation of the liver (Fig. 4 ). Because the fibrous septa with arteries are the location of blood inflow, they can be considered "portal tract equivalents," i.e., they have the artery and the ductular reaction but not that of the bile duct and vein (39). In FNH, we observed an extension from the centrolobular equivalent area toward the portal tract equivalent. The blood composition may likely participate in zonal/restricted $\beta$-catenin activation. One could therefore hypothesize that the almost completely arterial inflow in FNH, without portal venous blood inflow, may cause $\beta$ -catenin activation to extend much farther toward the inflow area than in normal liver or in cirrhotic liver, where there is still some portal venous inflow. The mechanism of $\beta$-catenin activation in FNH remains to be elucidated since we did not identify any alteration of the main known regulators of the Wnt pathway. As such, we did not observe any variations in the expression level of negative regulators such as GSK3 $\beta$, AXIN1 and APC and positive regulators such as WNT, FZD (Frizzled), DVL and LRP (Supplementary Fig. 1 and 2). Moreover, in FNH we did not identify any activating mutations of $\beta$-catenin. Furthermore a previous work showed the lack of AXIN1 and APC inactivating mutations in those tumors (17).

Activation of the $\beta$-catenin pathway in FNH could consequently contribute to tumor formation as $\beta$-catenin may promote hepatocyte proliferation and regeneration. However, in contrast to an activating mutation, hepatocytes in FNH remain sensitive to repression of the $\beta$ -catenin pathway in regions surrounding fibrosis. The present study also shows that fibrosis in FNH is related to the overexpression of several genes encoding extracellular matrix proteins, in addition to increased TGF- $\beta$ expression. This result is in agreement with in situ hybridization experiments in which a high expression level of TGB- $\beta 1$ was detected in mesenchymal cells in FNHs (40). TGF- $\beta 1$ is a multifunctional cytokine that is involved in development and tissue differentiation through its effects on cell proliferation, migration, differentiation, and apoptosis. TGF $\beta-1$ is also important in the pathological process of fibrosis. Interestingly, TGF- $\beta$ and Wnt/ $\beta$-catenin pathways regulate a number of common processes during embryonic development, such as the patterning of imaginal discs in Drosophila and tissue specification and organogenesis in vertebrate embryos (41). Several recent reports have highlighted the complex, intertwined nature of the two signaling pathways (42). Zhang and collaborators supported the hypothesis that $\beta$-catenin in renal epithelial cells, rather than in mesenchymal cells, may suppress TGF- $\beta 1$-dependent signaling (43). Furthermore, analysis of TGF- $\beta 1$ transgenic mice showed reduced GS expression resulting from apoptosis of GS-positive hepatocytes (44). However, Lotz and collaborators showed that in FNH, TGF- $\beta$ activation was not related to increased hepatocyte apoptosis (40). Consequently, additional functional analyses of the interplay between TGF- $\beta$ and $\beta$-catenin pathways in hepatocytes are required to better understand the pathogenesis of FNH. One hypothesis could be proposed in which TGF $\beta$ overexpression in FNH may occur to counteract the proliferative effect of $\beta$-catenin activation. In another hypothesis, $\beta$-catenin activation could represent a response to an abnormal TGF $\beta$-activation in FNH. Considering that most frequent FNH remain stable, activation of these pathways is probably tightly controlled to balance cell proliferation rate.

Another important finding of our study was that FNH-like nodules gene expression profile significantly differs from that of typical FNH nodules. In particular, FNH-like nodules did not show $\beta$-catenin activation. Moreover, they did not exhibit increased NTS/HAL expression ratio as did typical FNH. None of the genes tested in FNH-like nodules demonstrated a significantly different level of expression from that of random cirrhotic samples or cirrhotic dysplastic nodules. Our results demonstrate that, despite an enhancement of the signal during the arterial phase in MR/CT imaging of both types of nodules, typical FNH and FNH-like nodules derive from different pathophysiological processes. The specific markers identified in the present study will be useful tools to correctly diagnose and classify benign lesions of the liver, including the different molecular subtypes of HCA (22).

In conclusion, abnormally zonated $\beta$-catenin activation is a particular feature of typical FNH that may explain the slight polyclonal over-proliferation of hepatocytes at the origins of the lesions. In contrast, FNH-like nodules, as random cirrhosis, do not share the same molecular defect, indicating a different pathogenesis. Finally, molecular and immunohistochemical markers will be useful tools in clinical practice to diagnose and classify benign hepatocellular tumors.

\section{Ackowledgements:}


We thank Eric Chevet for critical reading of this manuscript. This work was supported by Inserm (Réseaux de recherche clinique et réseaux de recherche en santé des populations), the comité Dordogne de la Ligue contre le Cancer, the SNFGE and the program "Carte d'identité des tumeurs" by the ligue Nationale Contre le Cancer. SR is supported by a Ligue Nationale Contre le Cancer doctoral fellowship.

\section{Abbreviations}

FNH: Focal Nodular Hyperplasia

HCA: hepatocellular adenoma

RT-PCR: Reverse Transcriptase Polymerase Chain Reaction

GLUL: gene coding for glutamine synthetase

GS: Glutamine Synthetase

AAT1: alpha-1 antitrypsin deficiency

APC: adenomatosis polyposis coli

CTNNB1: gene coding for beta-catenin

ANGPT1 and ANGPT2: genes coding for angiopoietin 1 and 2, respectively

HNF1a: hepatocyte nuclear factor 1 alpha

TCF1: transcription factor 1 (gene coding for HNF1alpha)

HGDN: high-grade dysplastic nodules

LGDN: low-grade dysplastic nodules

MRN: macroregenerative nodules

GSK3beta: glycogen synthase kinase 3 beta

\section{References:}

- 1. Edmondson HA Tumors of the liver and intrahepatic bile ducts. Atlas of tumor pathology. Washington, DC Armed Forces Institute of Pathology; 1958;

- 2. Rebouissou S , Bioulac-Sage P, Zucman-Rossi J Molecular pathogenesis of focal nodular hyperplasia and hepatocellular adenoma. J Hepatol. 2008; 48 : 163- 170

- 3. Wanless IR, Mawdsley C , Adams R On the pathogenesis of focal nodular hyperplasia of the liver. Hepatology. 1985; 5: 1194- 200

- 4. Vilgrain V, Flejou JF , Arrive L, Belghiti J , Najmark D, Menu Y Focal nodular hyperplasia of the liver: MR imaging and pathologic correlation in 37 patients. Radiology 1992; 184: 699- 703

- 5. Bioulac-Sage P, Balabaud C , Wanless IR Diagnosis of focal nodular hyperplasia: not so easy. Am J Surg Pathol. 2001; 25: 1322- 5

- 6. Cherqui D, Rahmouni A, Charlotte F, Boulahdour H, Metreau JM, Meignan M Management of focal nodular hyperplasia and hepatocellular adenoma in young women: a series of 41 patients with clinical, radiological, and pathological correlations. Hepatology. 1995; 22: 1674- 81

- 7. Terminology of nodular hepatocellular lesions. International Working Party Hepatology. 1995; 22: 983 - 93

- 8. Bioulac-Sage P, Balabaud C, Bedossa P, Scoazec JY, Chiche L, Dhillon AP Pathological diagnosis of liver cell adenoma and focal nodular hyperplasia: Bordeaux update J Hepatol. 2007; 46: 521- 7

- 9. Fukukura Y, Nakashima O , Kusaba A , Kage M , Kojiro M Angioarchitecture and blood circulation in focal nodular hyperplasia of the liver. J Hepatol. 1998; 29: 470- 5

- 10. Wanless IR, Albrecht S, Bilbao J, Frei JV, Heathcote EJ, Roberts EA Multiple focal nodular hyperplasia of the liver associated with vascular malformations of various organs and neoplasia of the brain: a new syndrome. Mod Pathol. 1989; 2: 456- 62

- 11. Gaffey MJ , Iezzoni JC, Weiss LM Clonal analysis of focal nodular hyperplasia of the liver. Am J Pathol. 1996; 148: 1089- 96

- 12. Chen TC, Chou TB , Ng KF, Hsieh LL, Chou YH Hepatocellular carcinoma associated with focal nodular hyperplasia. Report of a case with clonal analysis. Virchows Arch. 2001; 438: 408- 11

- 13. Zhang SH, Cong WM , Wu MC Focal nodular hyperplasia with concomitant hepatocellular carcinoma: a case report and clonal analysis. J Clin Pathol. 2004; 57: 556- 9

- 14. Paradis V, Laurent A, Flejou JF, Vidaud M, Bedossa P Evidence for the polyclonal nature of focal nodular hyperplasia of the liver by the study of X-chromosome inactivation. Hepatology. 1997; 26: 891- 5

- 15. Bioulac-Sage P, Rebouissou S, Sa Cunha A, Jeannot E, Lepreux S, Blanc JF Clinical, morphologic, and molecular features defining so-called telangiectatic focal nodular hyperplasias of the liver. Gastroenterology. 2005; 128: 1211- 8

- 16. Chen YJ, Chen PJ , Lee MC, Yeh SH , Hsu MT , Lin CH Chromosomal analysis of hepatic adenoma and focal nodular hyperplasia by comparative genomic hybridization. Genes Chromosomes Cancer. 2002; 35: 138- 43

- 17. Chen YW, Jeng YM, Yeh SH, Chen PJ P53 gene and Wnt signaling in benign neoplasms: beta-catenin mutations in hepatic adenoma but not in focal nodular hyperplasia . Hepatology. 2002; 36: 927- 35

- 18. Blaker H, Sutter C, Kadmon M, Otto HF , Von Knebel-Doeberitz M, Gebert J Analysis of somatic APC mutations in rare extracolonic tumors of patients with familial adenomatous polyposis coli. Genes Chromosomes Cancer. 2004; 41: 93- 8

- 19. Libbrecht L, Cassiman D, Verslype C, Maleux G, Van Hees D, Pirenne J Clinicopathological features of focal nodular hyperplasia-like nodules in 130 cirrhotic explant livers. Am J Gastroenterol. 2006; 101: 2341- 6

- 20. Quaglia A , Tibballs J , Grasso A, Prasad N , Nozza P, Davies SE Focal nodular hyperplasia-like areas in cirrhosis. Histopathology. 2003; 42: 14- 21

- 21. Nakashima O, Kurogi M, Yamaguchi R, Miyaaki H, Fujimoto M, Yano H Unique hypervascular nodules in alcoholic liver cirrhosis: identical to focal nodular hyperplasia-like nodules?. J Hepatol. 2004; 41: 992- 8

- 22. Bioulac-Sage P, Rebouissou S, Thomas C, Blanc JF, Sa Cunha A, Rullier A Hepatocellular adenoma subtype classification using molecular markers and immunohistochemistry. Hepatology. 2007;

- 23. Zucman-Rossi J , Jeannot E, Nhieu JT , Scoazec JY, Guettier C, Rebouissou S Genotype-phenotype correlation in hepatocellular adenoma: new classification and relationship with HCC. Hepatology. 2006; 43: 515- 24

- 24. Graudens E, Boulanger V , Mollard C, Mariage-Samson R, Barlet X, Gremy G Deciphering cellular states of innate tumor drug responses. Genome Biol. 2006; 7: R19-

- 25. Rebouissou S, Vasiliu V, Thomas C, Bellanne-Chantelot C, Bui H, Chretien Y Germline hepatocyte nuclear factor 1alpha and 1beta mutations in renal cell carcinomas. Hum Mol Genet. 2005; 14: 603- 14

- 26. Benhamouche S, Decaens T, Godard C, Chambrey R, Rickman DS , Moinard C Apc tumor suppressor gene is the "zonation-keeper" of mouse liver. Dev Cell. 2006; 10: 759- 70

- 27. Braeuning A, Ittrich C, Kohle C, Buchmann A, Schwarz M Zonal gene expression in mouse liver resembles expression patterns of Ha-ras and beta-catenin mutated hepatomas. Drug Metab Dispos. 2007; 35: 503- 7 
- 28. Cadoret A, Ovejero C, Terris B, Souil E, Levy L, Lamers WH New targets of beta-catenin signaling in the liver are involved in the glutamine metabolism. Oncogene. 2002; $21: 8293-301$

- 29. Paradis V, Bieche I, Dargere D, Laurendeau I, Nectoux J, Degott C A quantitative gene expression study suggests a role for angiopoietins in focal nodular hyperplasia. Gastroenterology. 2003; 124: 651-9

- 30. de La Coste A, Romagnolo B, Billuart P, Renard CA, Buendia MA, Soubrane O Somatic mutations of the beta-catenin gene are frequent in mouse and human hepatocellular carcinomas. Proc Natl Acad Sci U S A. 1998; 95: 8847- 51

- 31. Miyoshi Y, Iwao K, Nagasawa Y, Aihara T, Sasaki Y, Imaoka S Activation of the beta-catenin gene in primary hepatocellular carcinomas by somatic alterations involving exon 3. Cancer Res. 1998; 58: 2524- 7

- 32. Monga SP , Monga HK, Tan X , Mule K, Pediaditakis P, Michalopoulos GK Beta-catenin antisense studies in embryonic liver cultures: role in proliferation, apoptosis, and lineage specification. Gastroenterology. 2003; 124: 202- 16

- 33. Monga SP, Pediaditakis P, Mule K, Stolz DB , Michalopoulos GK Changes in WNT/beta-catenin pathway during regulated growth in rat liver regeneration. Hepatology. 2001; 33: 1098- 109

- 34. Tan X , Behari J , Cieply B , Michalopoulos GK , Monga SP Conditional deletion of beta-catenin reveals its role in liver growth and regeneration. Gastroenterology. 2006; 131: $1561-72$

- 35. Moorman AF, de Boer PA, Geerts WJ , van den Zande L, Lamers WH, Charles R Complementary distribution of carbamoylphosphate synthetase (ammonia) and glutamine synthetase in rat liver acinus is regulated at a pretranslational level. J Histochem Cytochem. 1988; 36: 751- 5

- 36. Lepreux S, Desmouliere A, Rosenbaum J , Balabaud C, Bioulac-Sage P Expression of fibrillin-1 in focal nodular hyperplasia of the liver: a role in microcirculation adaptability. Comp Hepatol. 2004; 3 : (Suppl 1) S57-

- 37. Scoazec JY, Flejou JF, D'Errico A, Couvelard A, Kozyraki R, Fiorentino M Focal nodular hyperplasia of the liver: composition of the extracellular matrix and expression of cell-cell and cell-matrix adhesion molecules. Hum Pathol. 1995; 26: 1114- 25

- 38. Theuerkauf I, Zhou H , Fischer HP Immunohistochemical patterns of human liver sinusoids under different conditions of pathologic perfusion. Virchows Arch. 2001; 438: 498- 504

- 39. Butron Vila MM, Haot J , Desmet VJ Cholestatic features in focal nodular hyperplasia of the liver. Liver. 1984; 4: $387-95$

- 40. Lotz G, Nagy P, Patonai A, Kiss A, Nemes B , Szalay F TGF-beta and apoptosis in human hepatocellular carcinoma and focal nodular hyperplasia. J Hepatol. 1998; 28: $175-$

- 41. Nusse R Wnt signaling in disease and in development. Cell Res. 2005; 15: 28- 32

- 42. Labbe E, Lock L, Letamendia A, Gorska AE, Gryfe R, Gallinger S Transcriptional cooperation between the transforming growth factor-beta and Wnt pathways in mammary and intestinal tumorigenesis. Cancer Res. 2007; 67: 75- 84

- 43. Zhang M , Lee CH, Luo DD, Krupa A, Fraser D , Phillips AO Polarity of response to TGF-beta 1 in proximal tubular epithelial cells (PTC) is regulated by beta -catenin. J Biol Chem. 2007;

- 44. Ueberham E, Arendt E, Starke M , Bittner R, Gebhardt R Reduction and expansion of the glutamine synthetase expressing zone in livers from tetracycline controlled TGF-beta1 transgenic mice and multiple starved mice. J Hepatol. 2004; 41: 75- 81 


\section{Figure 1}

Expression of the TGF $\beta$ and $\beta$-catenin pathways in FNH

(A, B) Two serial sections of FNH stained with Masson's trichrome (TC) showing fibrous bands stained in blue. (C, D, E) Immunostaining of collagen IV (Col IV) in NTL (C) and FNH (D, E). In NTL, some Co IV fibrils are found around vessels and biliary channels in portal tract; in FNH, immunostaining showed a diffuse pattern with more intense expression in and around fibrous bands (black arrows), also found along sinusoids. (F, G, H) Immunostaining of smooth muscle actin (SMA) in NTL (F) and FNH (G, H). In NTL, SMA is expressed only by myofibroblasts of vascular walls (black arrow): artery (right), central vein (left); in lobules, only a few hepatic stellate cells (HSC) express faintly SMA (red arrow); in FNH, SMA is overexpressed by myofibroblasts in and around fibrous bands (black arrow) and veins (red arrow). (I, J, K) Immunohistochemistry using GS antibody in non-tumor liver (NTL) (I) and FNH (J, K). In NTL, GS is expressed only by hepatocytes of 1 or 2 centrolobular plates (arrow); in FNH, typical aspect of GS staining in a "map-like" pattern (J); this large GS+ area is centered on a central vein and remains at a distance from the fibrous band (K). (L) Correlation between GLUL and CTNNB1 mRNA overexpression in FNH and in NTL. Expression of GLUL (encoding GS) and CTNNB1 (encoding $\beta$-catenin) was measured in FNH $(\mathrm{n}=11$ ) and in NTL $(n=6)$ with quantitative RT-PCR. (M, N, O) Immunohistochemistry using a total $\beta$-catenin antibody in NTL (M) and FNH (N, $\mathrm{O})$. In NTL, $\beta$-catenin immunostaining showed a normal membranous staining in hepatocytes and an obvious cytoplasmic staining in biliary cells (arrows); in FNH, no cytoplasmic nor nuclear $\beta$-catenin staining was observed in hepatocytes that overexpressed GS, but there was normal membranous expression. In fibrotic areas, biliary cells of the ductular reaction showed normal strong cytoplasmic expression of $\beta$ -catenin (arrows). (P) Overexpression of active, unphosphorylated $\beta$-catenin in FNH $(n=4)$ compared with NTL tissues $(n=4)$.

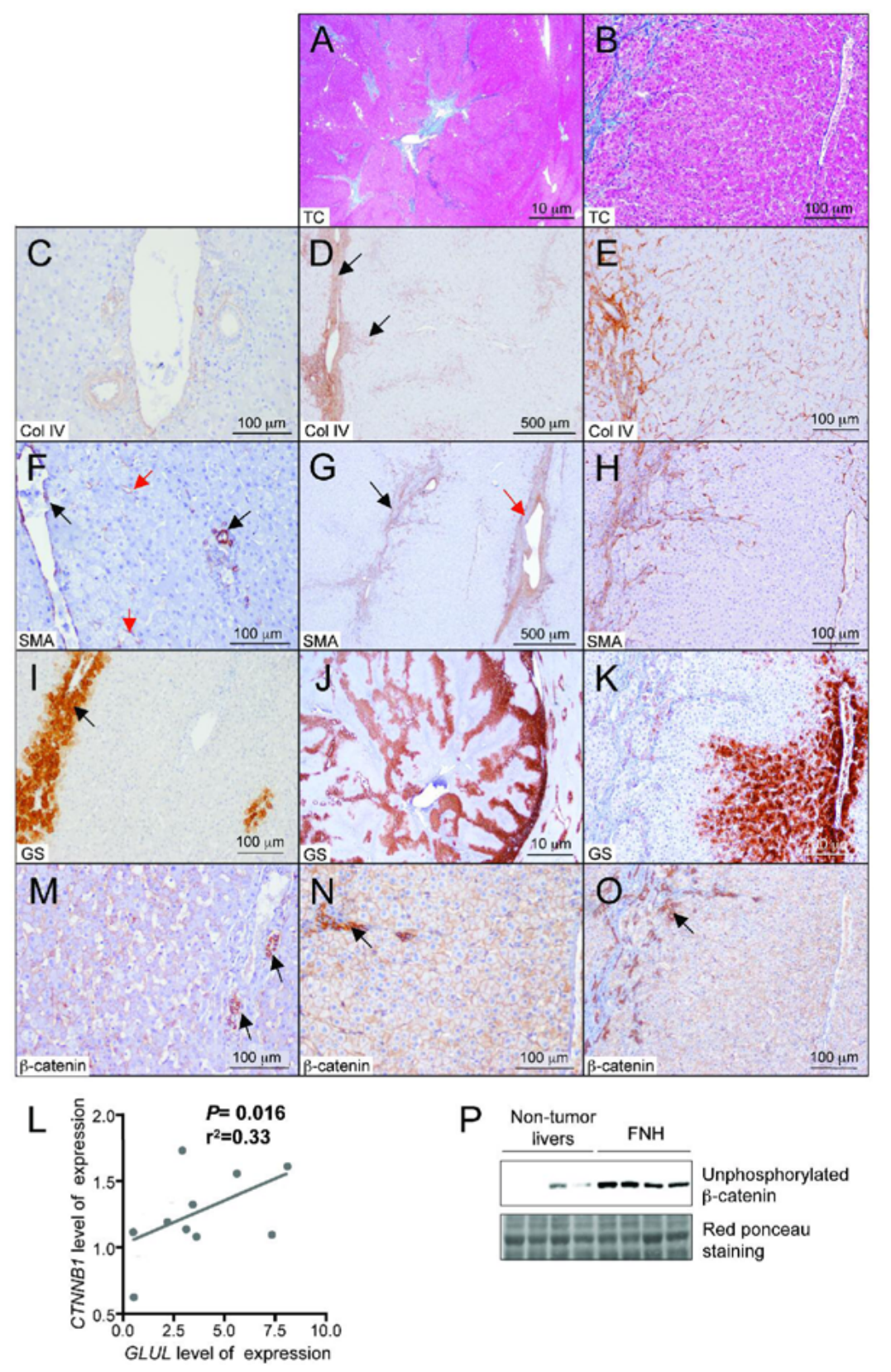




\section{Figure 2}

Validation of deregulated genes in well-defined subtypes of benign liver tumors

Gene expression was examined by quantitative RT-PCR in different subgroups of samples: N, normal liver samples $(n=6)$; FNH-like nodules $(n=11)$; Cirr N, dysplastic or macroregenerative nodules in cirrhosis $(n=8)$; Cirr, cirrhotic nodules $(n=19) ;$ FNH $(n=11)$; Inflam. Ad, inflammatory adenomas $(n=5)$; HNF1 Ad, HNF1 $\alpha$-mutated adenomas $(n=5)$; $\beta$-cat. Ad, $\beta$-catenin-mutated adenomas $(n=5)$. All results were normalized to the mean expression level of normal liver samples. When box-and-whiskers graphs are used, the line in the middle is the median, the box extends from the $25^{\text {th }}$ to $75^{\text {th }}$ percentile, and the whiskers extend to the lowest and highest values. Significant results of the Mann-Whitney test comparing expression of each subgroup of tumors with normal liver samples are indicated as follows: ${ }^{\star *} \mathrm{P}<0.01$, ${ }^{*} \mathrm{P}<$ 0.05 .
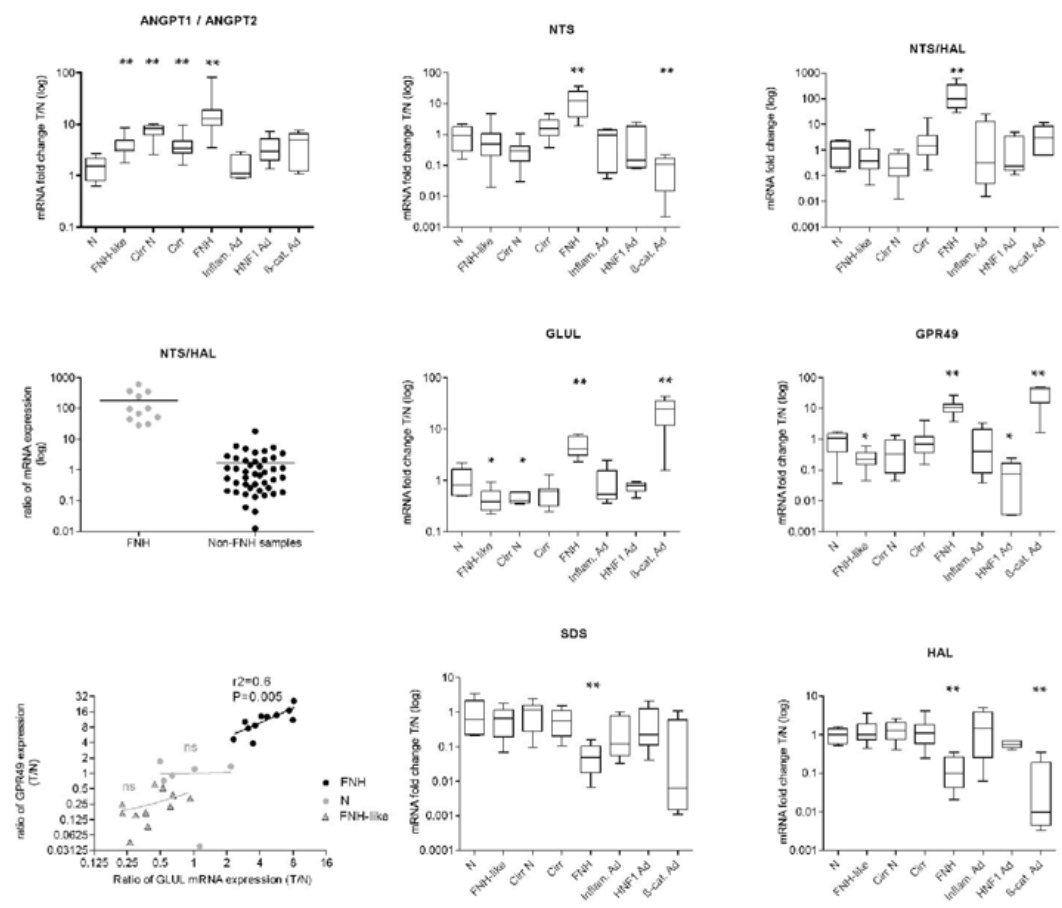


\section{Figure 3}

Expression of glutamine synthetase (GS) in FNH-like nodule and cirrhosis. (A) FNH-like nodule with a diameter of 9 mm (left side) and some surrounding regenerative cirrhotic nodules (S). The FNH-like nodule contains several septa that are surrounded by reactive ductules (arrows). (B) GS-staining of the FNH-like nodule and surrounding regenerative cirrhotic nodules. In the FNH-like nodules, there is staining of the reactive ductules (arrows), but parenchymal staining is very limited, in contrast to focal nodular hyperplasia. In the surrounding cirrhotic nodules, there is some patchy parenchymal staining, mostly related to venous structures (arrowheads).

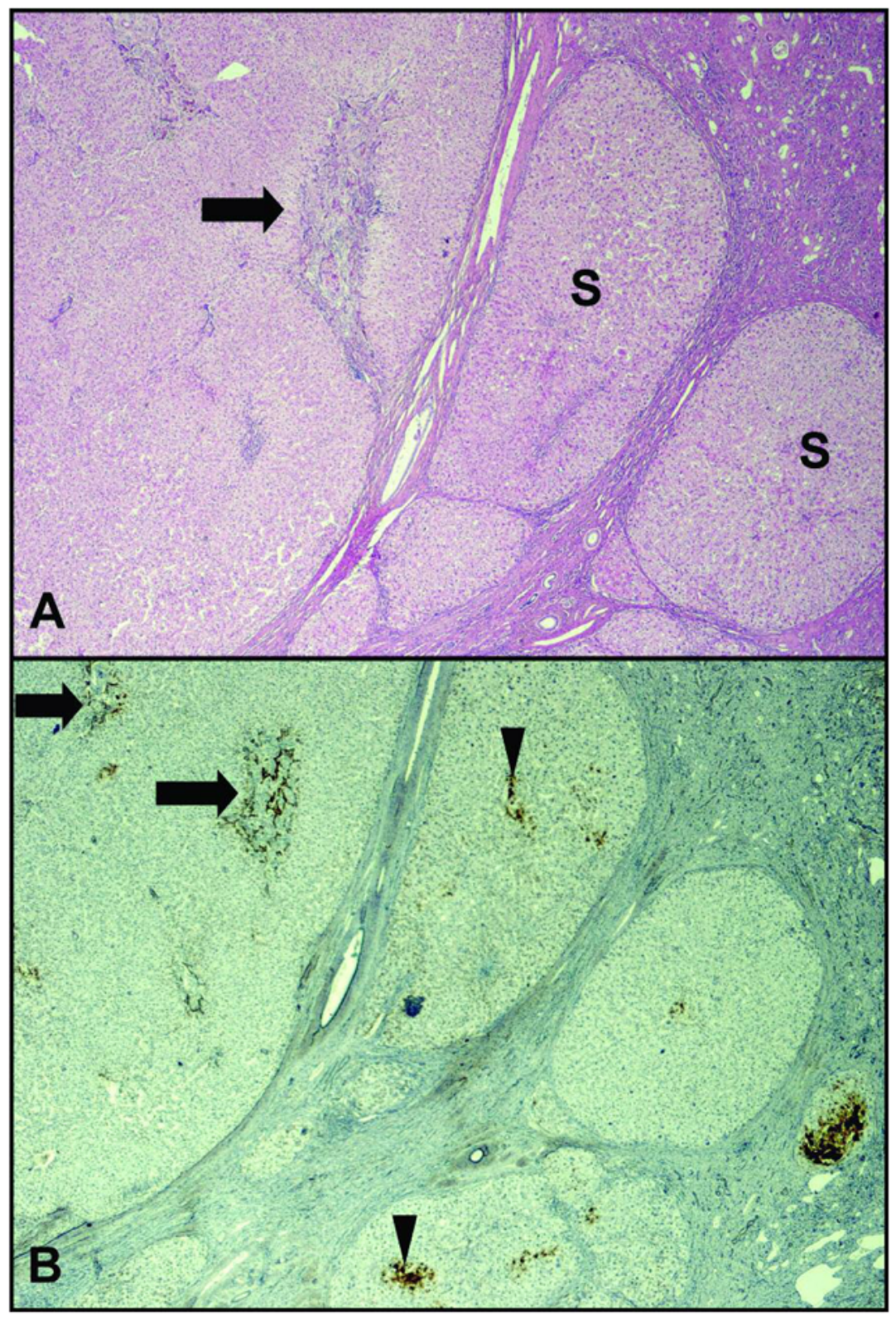




\section{Figure 4}

Schematization of glutamine synthetase staining in normal liver (A) and in FNH (B). GS staining is indicated in brown. CV, central vein; PT, portal tract; V, vein; DV, dystrophic vessels; fib, fibrosis (in grey); DR, ductular reaction; hep GS +, glutamine synthetase-positive hepatocytes; hep GS -, glutamine synthetase-negative hepatocytes.

A

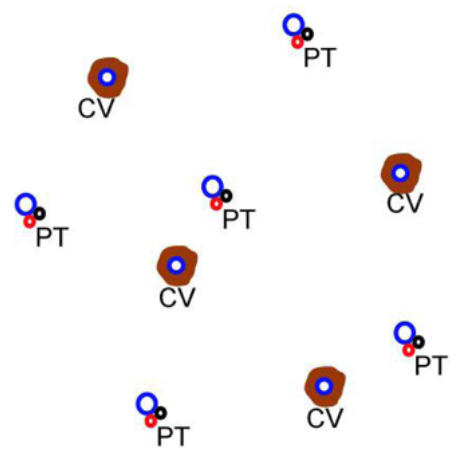

Normal liver
B

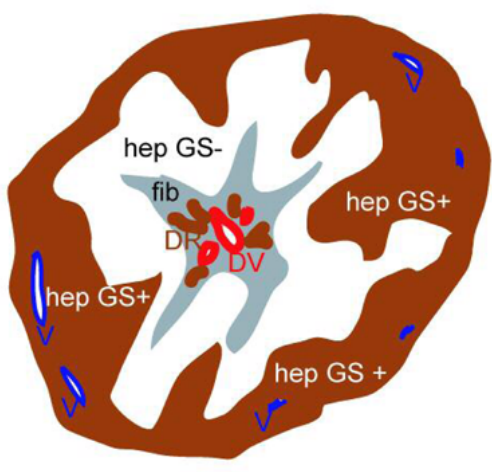

$\mathrm{FNH}$ 
Table 1

Clinical Features of Included Samples and Patients

\begin{tabular}{|c|c|c|c|c|c|c|c|}
\hline & $\begin{array}{l}\text { Number of analyzed } \\
\text { samples }\end{array}$ & $\begin{array}{c}\text { Number of } \\
\text { patients }\end{array}$ & $\begin{array}{l}\text { Age (mean } \pm \\
\text { SD) }\end{array}$ & $\begin{array}{c}\text { Gender } \\
\text { (F/M) }\end{array}$ & $\begin{array}{c}\text { Tumor diameter (mean } \pm \text { SD, } \\
\text { cm) }\end{array}$ & $\begin{array}{c}\text { Number of nodules } \\
\text { (mean) }\end{array}$ & $\begin{array}{l}\text { Risk factor of } \\
\text { cirrhosis }\end{array}$ \\
\hline Normal liver & 6 & 6 & $48 \pm 14$ & $6 / 0$ & & & - \\
\hline FNH & 11 & 8 & $41 \pm 7$ & $8 / 0$ & $5.1 \pm 1.8$ & 2 & - \\
\hline $\begin{array}{c}\text { Dysplastic and macroregenerative cirrhotic } \\
\text { nodules }\end{array}$ & 8 & 6 & $55 \pm 4$ & $3 / 3$ & $1.1 \pm 0.5$ & 4 & $\begin{array}{c}\mathrm{HCV}=3 \\
\text { Alcohol }=3\end{array}$ \\
\hline \multirow[t]{2}{*}{ Cirrhosis } & 19 & 16 & $60 \pm 7$ & $2 / 14$ & & & $\begin{array}{l}\mathrm{HCV}=9 \\
\mathrm{HBV}=3\end{array}$ \\
\hline & & & & & & & $\begin{array}{c}\text { Alcohol }=5^{*} \\
\text { AAT1 }=1\end{array}$ \\
\hline Inflammatory HCA & 5 & 5 & $39 \pm 7$ & $5 / 0$ & $5 \pm 3$ & 3 & - \\
\hline HNF1a-mutated HCA & 5 & 5 & $36 \pm 12$ & $4 / 1$ & $2.8 \pm 2.9$ & 3 & - \\
\hline$\beta$-catenin-mutated HCA & 5 & 5 & $47 \pm 14$ & $4 / 1$ & $3.3 \pm 2.2$ & 2 & - \\
\hline
\end{tabular}

* Two patients presented simultaneously with alcohol intake and hepatitis B viral (HBV) or hepatitis C viral (HCV) infection. AAT1: alpha-1 antitrypsin deficiency.

Table 2

Genes Encoding Extracellular Matrix Proteins Up-regulated in FNH

\begin{tabular}{|c|c|c|c|}
\hline Gene Symbol & Gene Name & Affymetrix Ratio 4FNH/4NTL & cDNA array Ratio \\
\hline \multicolumn{4}{|c|}{ Extracellular matrix } \\
\hline COL1A1 & Collagen. type I. alpha 1 & 19.8 & nd \\
\hline COL1A2 & Collagen. type I. alpha 2 & 9.3 & nd \\
\hline COL3A1 & Collagen. type III. alpha 1 & 9.8 & nd \\
\hline COL4A1 & Collagen. type IV. alpha 1 & 3.3 & nd \\
\hline COL4A2 & Collagen. type IV. alpha 2 & 5 & nd \\
\hline COL5A1 & Collagen. type V. alpha 1 & 4.3 & 2.4 \\
\hline COL5A2 & Collagen. type V. alpha 2 & 3.8 & nd \\
\hline COL6A1 & Collagen. type VI. alpha 1 & 2.5 & nd \\
\hline COL6A2 & Collagen. type VI. alpha 2 & 2 & 1.4 \\
\hline COL15A1 & Collagen. type XV. alpha 1 & 3.1 & 1.7 \\
\hline CSPG2 & Chondroitin sulfate proteoglycan 2 (versican) & 5.8 & 1.7 \\
\hline $\mathrm{DCN}$ & Decorin & 1.9 & na \\
\hline EFEMP1 & EGF-containing fibulin-like extracellular matrix protein 1 & 9.5 & nd \\
\hline FBLN2 & Fibulin 2 & 2.6 & nd \\
\hline FBLN5 & Fibulin 5 & 4 & nd \\
\hline FBN1 & Fibrillin 1 (Marfan syndrome) & 3.2 & nd \\
\hline FLRT2 & Fibronectin leucine-rich transmembrane protein 2 & 2.1 & nd \\
\hline
\end{tabular}

FLRT2 Fibronectin leucine-rich transmembrane protein 2 


$\begin{array}{ll}\text { HSPG2 } & \text { Heparan sulfate proteoglycan 2 (perlecan) } \\ \text { IBSP } & \text { Integrin-binding sialoprotein (bone sialoprotein II) } \\ \text { LAMA2 } & \text { Laminin. alpha 2 (merosin) } \\ \text { LAMB2 } & \text { Laminin. beta 2 (laminin S) } \\ \text { LOXL4 } & \text { Lysyl oxidase-like 4 } \\ \text { LUM } & \text { Lumican } \\ \text { MGP } & \text { Matrix Gla protein } \\ \text { MMP11 } & \text { Matrix metalloproteinase 11 (stromelysin 3) } \\ \text { MMP2 } & \text { Matrix metalloproteinase 2 } \\ \text { PRG4 } & \text { Proteoglycan 4 } \\ \text { SPARC } & \text { Secreted protein. acidic. cysteine-rich (osteonectin) } \\ \text { SPON2 } & \text { Spondin 2 } \\ \text { TFPI2 } & \text { Tissue factor pathway inhibitor 2 } \\ \text { TGFBI } & \text { Transforming growth factor, beta-induced, 68 kDa } \\ \text { THBS2 } & \text { Thrombospondin 2 } \\ \text { TIMP1 } & \text { Tissue inhibitor of metalloproteinase 1 } \\ \text { TNC } & \text { Tenascin C (hexabrachion) } \\ \text { TNXB } & \text { Tenascin XB } \\ \text { VWF } & \text { Von Willebrand factor }\end{array}$

\section{Cell matrix adhesion}

$\begin{array}{ll}\text { ADAM15 } & \text { A disintegrin and metalloproteinase domain 15 (metargidin) } \\ \text { EMCN } & \text { Endomucin } \\ \text { GPLD1 } & \text { Glycosylphosphatidylinositol specific phospholipase D1 } \\ \text { ITGA6 } & \text { Integrin, alpha 6 } \\ \text { ITGAV } & \text { Integrin, alpha V (vitronectin receptor, antigen CD51) } \\ \text { ITGBL1 } & \text { Integrin, beta-like 1 (with EGF-like repeat domains) } \\ \text { SGCE } & \text { Sarcoglycan, epsilon } \\ \text { XLKD1 } & \text { Extracellular link domain containing 1 }\end{array}$

\section{Fibrogenesis pathway}

\begin{tabular}{llcl}
\hline TGFB1 & Transforming growth factor. beta 1 & 2.2 & -1.2 \\
ENG & Endoglin (Osler-Rendu-Weber syndrome 1) & 2.7 & $\mathrm{~ns}$ \\
TGIF2 & TGFB-induced factor 2 (TALE family homeobox) & 2.3 \\
PDGFA & Platelet-derived growth factor alpha polypeptide & -2.2 \\
PDGFRB & Platelet-derived growth factor receptor, beta polypeptide & nd \\
TGFB1I1 & Transforming growth factor beta 1 induced transcript 1 & 2.2 & $\mathrm{~ns}$ \\
ns: not significant; na: not analyzed; nd: not done; NTL: non tumor-livers & 1.9
\end{tabular}


Table 3

Known Zonated and $\beta$-Catenin Target Genes Deregulated in FNH

\begin{tabular}{|c|c|c|c|c|c|}
\hline $\begin{array}{l}\text { Gene } \\
\text { Symbol }\end{array}$ & Gene Name & $\begin{array}{c}\text { Affymetrix Ratio } \\
\text { 4FNH/4NTL } \\
\end{array}$ & $\begin{array}{c}\text { cDNA array Ratio } \\
\text { 7FNH/8NTL } \\
\end{array}$ & Function & $\begin{array}{c}\text { Known effect of } \beta \text {-catenin } \\
\text { activation }\end{array}$ \\
\hline \multicolumn{6}{|c|}{ Periportal genes } \\
\hline SDS & Serine dehydratase & -20.2 & nd & amino acid catabolism & Repressed \\
\hline GLS2 & Glutaminase 2 (mitochondrial) & -18.9 & nd & amino acid catabolism & Repressed \\
\hline HAL & Histidine ammonia-lyase & -5.9 & nd & amino acid catabolism & Repressed \\
\hline SDSL & Serine dehydratase-like & nd & -2.2 & amino acid catabolism & \\
\hline ASS & Argininosuccinate synthetase & -2.4 & -2.1 & amino acid catabolism & Repressed \\
\hline CPS1 & Carbamoyl-phosphate synthetase 1 mitochondrial & -2.2 & -1.6 & amino acid catabolism & \\
\hline GLDC & Glycine dehydrogenase & -2.3 & nd & amino acid catabolism & Repressed \\
\hline GNMT & Glycine N-methyltransferase & -6.5 & nd & amino acid metabolism & Repressed \\
\hline SLC7A2 & $\begin{array}{l}\text { Solute carrier family } 7 \text { (cationic amino acid transporter, } y+\text { system), } \\
\text { member } 2\end{array}$ & -2.2 & nd & amino acid transporter & Repressed \\
\hline IGF1 & Insulin-like growth factor 1 (somatomedin C) & -2.7 & -3.5 & growth factor & Repressed \\
\hline ALDOB & Aldolase B. fructose-bisphosphate & -2.3 & ns & glycolysis & Repressed \\
\hline HES 1 & Hairy and enhancer of split 1 & -2.7 & -2.2 & transcriptional regulator & Repressed \\
\hline CYP1A1 & Cytochrome P450, family 1 , subfamily A, polypeptide 1 & na & -1.9 & xenobiotic metabolism & \\
\hline
\end{tabular}

\section{Pericentral genes}

\begin{tabular}{|c|c|c|c|c|c|}
\hline GLUL & Glutamate-ammonia ligase (glutamine synthase) & 3.7 & 2.3 & glutamine synthesis & Induced \\
\hline RHBG & Rhesus blood group. B glycoprotein & 6.1 & nd & ammonium transporter & Induced \\
\hline LGR5 & Leucine-rich repeat-containing G protein-coupled receptor 5 & 2 & nd & receptor & Induced \\
\hline TBX3 & T-box 3 (ulnar mammary syndrome) & 3.1 & ns & transcriptional regulator & Induced \\
\hline SLC13A3 & $\begin{array}{l}\text { Solute carrier family } 13 \text { (sodium-dependent dicarboxylate transporter) } \\
\text { member } 3\end{array}$ & 2.6 & nd & $\begin{array}{l}\text { dicarboxylic acid } \\
\text { transporter }\end{array}$ & Induced \\
\hline SERPINE2 & Serine (or cysteine) proteinase inhibitor member 2 & 2.2 & nd & regulation of proteolysis & \\
\hline
\end{tabular}

\section{Other genes regulated by $\beta$-catenin}

\begin{tabular}{|c|c|c|c|c|c|}
\hline LAMA3 & Laminin, alpha 3 & 4.9 & 1.7 & extracellular matrix & Induced \\
\hline CCND1 & Cyclin D1 (PRAD1: parathyroid adenomatosis 1) & 3.1 & 1.6 & cell cycle & Induced \\
\hline SOX9 & SRY (sex determining region Y)-box 9 & 4.1 & nd & transcriptional regulator & Induced \\
\hline SOX4 & SRY (sex determining region Y)-box 4 & 2.2 & ns & transcriptional regulator & Induced \\
\hline ABCB1 & ATP-binding cassette. sub-family B (MDR/TAP). member 1 & 2 & na & $\mathrm{ABC}$ transporter & Induced \\
\hline FOSB & FBJ murine osteosarcoma viral oncogene homolog B & -4.3 & -2.2 & transcriptional regulator & Repressed \\
\hline FOS & V-fos FBJ murine osteosarcoma viral oncogene homolog & na & -4.6 & transcriptional regulator & Repressed \\
\hline
\end{tabular}

ns: not significant; na: not analyzed; nd: not done; NTL: non tumor-livers 